\title{
Keberfungsian Keluarga dan Kecanduan Internet pada Mahasiswa
}

\author{
Thobagus Moh. Nu' man ${ }^{1}$ \\ thobagus.mn@uii.ac.id \\ ${ }^{1}$ Islamic University of Indonesia
}

\begin{abstract}
Abstrak
Kecanduan intern et menjadi ancaman bagi kesehatan individu maupun masyara kat secara luas. Keberfungsian keluarga yang buruk dipandang s ebagai fakt or r esiko bagi individu mengalami kecanduan intern et Penelitian ini berupaya untu k mengungkap peran keberfungsian keluarga dalam kaitannya dengan kecanduan internet Penelitian ini melibatkan 198 mahasisw a s ebagai responden penelitian. Skala ke canduan internet $(\mathrm{a}=0.830)$ digunakan untuk mengungkap kecanduan internet, sedangkan keberfungsian keluarga diukur dengan skala Family Assesment Device $(\mathrm{a}=0.886)$. Hasil penelitian menunjukkan bahwa keberfungsian keluarga memiliki ko relasi yang sangat signifikan dengan kecanduan inter net $(\mathrm{r}=-0.398 ; \mathrm{p}<0,01)$. Keberfungsian keluarga yang buruk dapat memprediksi kecenderungan seseorang untuk mengalami kecanduan internet.
\end{abstract}

Kata Kunci : Kecanduan internet, Keberfungsian keluarga, Mahasiswa

Abstract

Internet addiction is a threat to the health of individuals and society at large. Poor family functioning is seen as a risk factor for individuals experiencing internet addiction. This study seeks to uncover the role of family functioning in relation to inter net addiction. This study involved 198 students as res earch respondents. The int ernet addiction scale $(a=0.830)$ was used to reveal the internet addiction, while the functioning of the family was measured by the scale of the Family Assessment Device $(a=0.886)$. The res ults showed that family functioning had a very significant cor re lation with internet addiction $(r=-0.398 ; p<0.01)$. Poo $r$ family functioning can predict one's tendency to experience internet addiction.

Keywords: Internet addiction, Family functioning, college students

Pengguna internet di Indonesia pada tahun 2014 mencapai 83.7 juta pengguna, yang membuat Indon esia mendu duki perin gkat 6 sebagai Negar a dengan pengguna ter besar di Dunia (Yusuf, 2014). Hal ini menunjukkan bahwa internet sudah menjadi kebutuhan masyarakat modern. Internet di satu sisi memiliki banyak manfaat namun di sisi yang lain tidak dapat dipungkiri internet juga memiliki sis i negatif. Dua mata pis au internet, sisi poistifsekaligus menghadirkansisi negatif, menunjukkan adanya internet paradox (Kraut et al, 1998). Pengguna intern et memanfaatkan internet sebagaialat komunikasi, n amun di sisi yang lain internet seringkali membuat partisipasi komunikasi antar anggota keluarga menjadi menurun, bahkan ditemukan internet membuat seseorang menjadi depresi dan kesepian (Kraut et al, 1998).

Salah satu yang dipandang sebagai persoalan besar terkait dengan internet adalah kecanduan internet (internet a ddiction). Studi yang dilakukan oleh Chou dan Hsio (Shek, Tang, 
\& Lo, 2008) pada 910 siswa di Taiwan ditemukan 5,9\% diantaranya diklasifikasikan sebagai pecandu int ernet, sedangkan Lin dan Yan (Shek et al, 2008) dari 293 responden China datar an ditemukan 9,6\% diantaranya diklasifikasikan sebagai pecandu internet. Pada kasus di In do nesia, berdas arkan data yang dirilis oleh Quartz (Heriy anto, Agustus 2014) Indonesia menduduki peringkat pertama terkait dengan jumlah jam penggunaan internet Pengguna internet di Indonesia ratarata menggunakan inter net 9 jam per hari. Jumlah jam penggunaan internet berkaitan dengan toleransi terhadap waktu penggunaan internet dan jumlah waktu penggunaan y ang lebih banyak daripada non-adiksi (Chou, Condron, \& Belland, 2005; Kuss \& Griffiths, 2015; Young, 1998).

Young (1998) mendefinisikan kecanduan internet sebagaimana kriteria patologi perjudian, yaitu ganggu an kontrol-impuls yang tidak melibatkan zat yang memabukkan. Kecanduan internet dikonseptualisasikan sebagai kecanduan perilaku yang melibatkan penggunaan berlebihan aplikasi online dan mengarah pada dampak merugikan pada kehidupan individu ters ebut (Kuss \& Griffiths, 2015). Secara umum, kecanduan internet dikelompokkan sebagai kecanduan teknologi (Widyanto \& Griffiths, 2007), yaitu kecanduan non-kimia (perilaku)yangmelibatkan interaksi mesin-manus ia. Kecanduan intern et paling tidak memenuhi komponen inti kecanduan yaitu, arti penting (salience), modifikasi mood, toleransi, penarikan diri (withdrawal),konflik, dan kambuh (relapse) (Widyanto \& G riffiths, 2007). Ada banyak istilah yang terkait dengan kecanduan internet yang seringkali digunakan secara silih berganti. Ist ilah-istilah tersebut antara lain Internet abuse, Internet dependency, compulsive Internet use, pathological Internet use dan problematic Internet use (MorahanMartin, 2008). Meskipun demikian semua istilah ters ebut hampir sama merujuk kepada pola penggunaan intern et berlebihan yang mengakibatkan gangguan dalam kehidupan seseorang tetapi tidak menyiratkan proses penyakit tertentu atau perilaku kecanduan (Morahan-Martin, 2008).

Kecanduan internet, dari berbagai penelitian, ditemukan memiliki dampak dalam berbagai as pek kehidupan manusia mulai dari masalah personal sampai dengan masalah interpers onal. Individu yang kecanduan internet dilaporkan mengalami kegagalan untuk berfungsi sebagaimana semestinya, misalkan kegaglan dalam mengatur waktu (misalkan, mengabaikan tugas sekolah atau pekerjaan) k urang tidur, dan kur ang makan (Brenner, 1997; Spada, 2014). Pada mahasisw a, kecanduan intern et b erdampak pada permasalahan pendidikan, dari nilai yang buruk, memperoleh peringatan untuk memperbaiki nilai agar tidak dikeluarkan dari unive rsitas, bahkan su dah dikeluar kan dari universitas (drop out) (Chou et al., 2005). Dampak negatif yang paling sering terjadi dengan kecanduan internet terkait dengan 
interaksi so sial (Caplan \& High, 2011). Hal ini dapat dimaklumi karena penggunaan internet seringkali difungs ikan s ebagai media untuk berinteraksi dengan or ang lain (MorahanMartin, 2008). Pecandu intern et ditemukan cenderung mengalami kesepian, hal ini disebabkan karena alo kasi waktu penggunaan inter net yang berlebihan mengurangi relasi dalam dunia nyata (Morahan-Martin \& Sch umacher, 2003). Per soalan lain terk ait dengan interk si sosial, kecanduan internet ditemukan berhubungan dengan masalah ko nflik dengan atasan dan mengalami i solasi sosial (Brenner, 1997). Ketidak mampuan untuk membangun relasi dengan orang lain dimungkinkan terjadik arena pecandu internet dikarakteristikkan dengan rendahnya efikasi sosial (Iskender \& Akin, 2010).

Menurut ecological model (Bronfenbrenner, 1979), keluarga merupakan bagian terdekat dan paling be rpengaruh dari lingkungan ekologis terh adap perkembangan manusia. Berdasarkan hal tersebut penelitian ini memfokuskan pada peran keluarga ter hadap kecenderungan kecanduan inter net pada mahasiswa. Penelitan sebelumnya men unjukkan b ahwa keluarga menjadi salah satu faktor yang signifikan terhadap kecenderungan anak mengalami kecanduan internet. Park, Kim, dan Cho (dalam Kuss \& Griffiths, 2015) menyatkan sikap pengasuhan yang positif ayah dan ibu, komunikasi keluarga dan kohesivitas keluarga sebagai faktor protektif anak mengalami kecanduan internet.
Secara khusu s, Ko, Yen, Yen, Lin, \& Yang (2007) menunjukkan bahwa keberfungsian kelu arga yang rendah merupakan faktor prediktif yang kritis terhadap ketergantungan internet.

Keberfungsian keluarga dalam model McMaster (Epstein, Baldwin, \& Bishop, 1983) idefinis kan sebagai pembeda antara keluarga yang sehat dan keluargayang tidak sehat. Lebih lanjut, keberfungsian keluarga dipandang sebagai sebuah konsep yang multidimensional yaitu keluarga yang memiliki komunikasi terbuka antar anggota keluarga, mampu untuk memecahkan permasalahan yang terjadi, memiliki ketertarikan pada aktivitas keluarga dan dapat merespon perasaan afektif pada anggo ta keluar ga secara tepat, serta memiliki kontrol peri laku yang jelas (Epstein, Bishop, \& Levin, 1978; Miller, Ry an, Keitn er, B ishop, \& Epstein, 2000). Pendapat lain mengenai batasan keberfungs ian keluarga disampaikan oleh Beavers \& Hampson (2000), yang mendefinisikan keberfungsian keluarga sebagai kons ep yang memiliki dua dimensi yaitu kompetensi keluarga dan gaya keluarga. Kompetensi keluarga berkaitan dengan struktur, ketersediaan informasi dan fleksibilitas adaptif sistem keluarga, sedangkan gaya keluarga merujuk pada gaya in ter aksi keluarga. Preechawong et al. (2007) mendefiniskan keberfun gsian keluarga sebagai cara anggota keluarga berinteraksi dan membangun hubungan satu sama lain termasuk pencapaian tujuan, aktivitas- 
aktivitas bersama, dan penerimaan pada rutinitas keluarga.

Keberfungsian keluarga dipandang sebagai faktor penting terkait dengan perilaku adiktif. Ada peningkatan kecanduan pada remaja yang hidup dalam keluarga yang dikar akteristikkan dengan lemahnya i katan emosional dan adaptasi keluarga (Tafà \& Baiocco, 2009). Lebi h spesifik, Yen, Yen, Chen, Chen, \& Ko (2007) menunjukkan bahwa keberfungsian keluarga yang rendah dapat mempr ediksi kecanduan internet. Orangtua memiliki peran yang sangat penting terhadap anak, terutama sebagai agen penting dan berpengar uh (Van Den Eijnden, Spijkerman, Vermulst, Van Rooij, \& Engels, 2010), lebih lanjut dijelaskan bahwa pengasuhan yang dilakukan oleh or angtua mungkin mendorong atau mencegah perkembangan masalahmasalah yangterkait denganinternet Liu \& Kuo (2007) menemukan hal yang sama, bahwa hubungan antara orang tua dan anak mempengaruhi kecanduan internet pada remaja.

Penelitian y ang dilakukan o leh Isfahani (2013) juga melihat peranan int ernal faktor keluarga terhadap kecenderungan kecanduan internet pada remaja putri. Penelitian ters ebut menemukan bahwa keterbukaan kom unikasi antara or ang tua dan anak dapat memprediksi kecenderungan kecanduan internet pada remaja putri. Penelitian yang dilakukan oleh Wartberg et al. (2014) menemukan bahwa keberfungsian keluarga memiliki peranan dalam masalah-masa lah penggu naan inter net pada remaja. Pandangan anak terhadap perilaku orangtua dan perilakunya sendi ri dalamkeluarga (self-functioning) sangat relevan dengan penggunaan internet yang berlebihan.

Berdasarkan beberapa peneltian di atas dapat disimpulkan bahwa keberfungsian keluarga sebagai prediktor bagi kecanduan intern et Rumusan hipotesis dalam penelitian ini adalah ada hubungan antara keber fungsian keluarga dan kecanduan internet, semakin kuat keberfungsian keluarga maka semakin rendah kecanduan internet pada mahasiswa.

\section{METODE PENELITIAN}

Respon den penelitian melibatk an 198 mahasiswa (64 laki-laki; 134 perempuan), berusia antara 17 - 24 tahun $(M=19.74$; $S D=1.619)$. Pengumpulan data dilakukan dengan menggunakan Skala keberfungsian keluarga yang diadaptasi dari Family Assesment Device (FAD). FAD merupakan a lat ukur yang dikembangkan oleh McMaster (Epst ein et al, 1983) berdasarkan teori McMaster (Miller et al, 2000). Skala ini terdiri atas 52 aitem yang mengukur 6 area dari keberfungsian keluarga yangmeliputi problemsolving, communication, affective involvement, affective responsiveness, behavior control dan roles serta general functioning.

Kecanduan internet akan diungkap dengan Skala kecanduan internet yang dikembangkan oleh Young (1998). Skala kecanduan internet mengukur beberapa 
dimensi diantaranya pengguna in ternet yang mengalami perasaan yang tidak menyenangkan a pabila tidak online; pengguna internet mengalami perasaan menyenangkan ketika online; memiliki perhatian yang tertuju pada internet; penggunaan internet yang semakin meningkat; ketidakmampuan dalam mengatur diri dalam menggunakan internet; ber ani mengambil resiko kehilangan karena internet; dan menggunakan internet sebagai cara melarikan diri dari masalah.

Berdasarkan uji reliabilitas alpha Cronbach, nilai reliabilitas Skala keberfungsian keluarga sebesar 0.886. Sedangkan nilai reliabilitas Skala kecanduan intern et sebesar 0.830. Pengujian hipotesis dalam penelitian ini menggunakan ko relasi prod uct moment dari pearson.

\section{HASI L PENELITIAN}

Sebanyak 198 (100\%) responden (64 laki-laki dan 134 perempuan) telah mengisi keseluruhan kuesioner, dan data ini yang dijadikan sebagai data yang akan dianal is is statistik. Data deskripsi yang ditunjukkan pada tabel 1 , usia rata-rata r esponden penelitian adalah $19.74 \pm 1.62$.

Tabel 1. Deskripsi data peneltian

\begin{tabular}{lr|r|r|r}
\hline & $\mathrm{N}$ & $\%$ & \multicolumn{1}{|c|}{ Mean } & Std. Deviation \\
\hline Usia, tahun & 198 & & 19.74 & 1.62 \\
Gender & & & & \\
$\quad$ Laki-laki & 134 & 32.3 & - & - \\
$\quad$ Perempuan & 198 & 67.7 & - & 17.092 \\
Kecanduan internet & 198 & - & 33.51 & 23.192 \\
\hline
\end{tabular}

Hasil analisis korelasi pearson ditampilkan pada tabel 2, menunjukkan bahwa ada kor elasi negatif y ang lemah ke sedang antara k eberfungsian k eluarga dan kecanduan inter net $(\mathrm{r}=-0.398, \mathrm{p}=0.000)$. Has il analis is untuk masing-masing aspek keberfungsian keluarga dan kecanduan internet ditemukan kor elasi negatif antara Peran dan kecanduan internet $(\mathrm{r}=-0.202, \mathrm{p}=0.002)$. Affective responsiveness ditemukan berkor elasi negatif dengan kecanduan internet $(r=-0.400$, $\mathrm{p}=0.000$ ). Begitu pula, affective involvement berkor elasi negatif dengan kecanduan internet $(\mathrm{r}=-0.320, \mathrm{p}=0.000)$. Kontrol perilaku (behavioural control) juga ditemukan berkor elasi negatif dengan kecanduan internet $(r=-0.274, p=0.000)$. Dimens i keberfungsian keluarga yang juga berk or elasi negatif dengan kecanduan internet adalah generic functioning $(\mathrm{r}=-0.36, \mathrm{p}=0.000)$.

Pada aspek komunikasi tidak ditemukan adanya korelasi dengan kecanduan intern et 
$(\mathrm{r}=0.018, \mathrm{p}=0.400)$. Begitu pula as pek

pemecahan masalah tidak ada korelasi dengan

kecanduan internet $(r=0.115, p=0.054)$.

Table 2. Kor elasi antara variabel kecanduan internet, keberfungsian keluarga dan aspek-aspek keberfungsian keluarga

\begin{tabular}{|c|c|c|c|c|c|c|c|c|c|c|}
\hline & & 1 & 2 & 3 & 4 & 5 & 6 & 7 & 8 & 9 \\
\hline 1 & Kecanduan internet & - & & & & & & & & \\
\hline 2 & Keberfungsian keluarga & $-.398^{\star *}$ & - & & & & & & & \\
\hline 3 & Problem solving & .115 & $.299^{* *}$ & - & & & & & & \\
\hline 4 & Komunikasi & .018 & $.365^{* *}$ & $.290^{\star *}$ & - & & & & & \\
\hline 5 & Peran & $-.202^{* *}$ & $.658^{* *}$ & .082 & -.024 & - & & & & \\
\hline 6 & Affective responsiveness & $-.400^{\star \star}$ & $.786^{* *}$ & $.219^{\star \star}$ & $.252^{*+}$ & $.456^{\star \star}$ & - & & & \\
\hline 7 & Affective involvement & $-320^{* *}$ & $.323^{* *}$ & -.063 & $.203^{\star *}$ & -.029 & $.188^{\star *}$ & - & & \\
\hline 8 & Behavioural control & $-.274^{\star *}$ & $.649^{* *}$ & .078 & .084 & $.386^{\star *}$ & $.326^{\star *}$ & .084 & - & \\
\hline 9 & Generic Functioning & $-.360^{\star *}$ & $.869^{* *}$ & .112 & $.149^{*}$ & $.561^{\star *}$ & $639^{* *}$ & .088 & $.559^{* *}$ & - \\
\hline
\end{tabular}

**. Correlation is significant at the 0.01 level (1-tailed).

*. Correlation is significant at the 0.05 level (1-tailed).

\section{DISKUSI}

Penelitian ini bertujuan untuk menyelidiki hubungan antara keberfungsian keluarga dan kecanduan internet. Hasil penelitian menunjukkan adanya kor elasi negatif antara keberfungsian kelaurga dan kecanduan internet. Artinya, semakin keluarga tidak berfungsi maka semakin tinggi kecenderungan anak untuk mengalami kecanduan internet.

Menurut ecological model (Bronfenbrenner, 1979) keluarga sebagai lingkungan terdekat an ak menjadi faktor yang signifikan dalam perkembangan anak, terutama interaksi antar anggota keluarga dipandang memiliki kontribusi yang paling besar terhadap tumbuh k embang anak. Anak akan tumbuh matang menjadi individu yang sehat saat mereka tumbuh di dalam keluarga yang berfungsi dengan baik. Banyak penelitian yang menunjukkan bahw a ketidakberfungsian keluraga berdampak kepada berbagai masalahmas alah klin is (Miller et al, 2000). Misalkan Lewandowski, Palermo, Stins on, Handley, dan Chamber s (2010) menemukan bahwa pada keluarga yang tidak berfungsi baik anak akan lebih merasakan nyeri kronis secara konsisten daripada keluarga yang berfungsi dengan sehat.

Hasil penelitian yang menunjukkan adanya hubungan negatif antara keberfungsian keluarga dengan kecanduan internet konsisten dengan beberapa penelitian sebelumnya. àenormanci, a enormanci, Güçlü, dan Konkan (2014) menemukan bahwa keberfungsian keluarga mampu memprediksi kecanduan internet pada remaja. Penelitian ini menggunakan FAD untuk mengukur keberfungsian keluarga dan ditemukan bahwa semua aspek dapat memprediks i kecanduan internet. Aspek komunikasi, peran dan keberfungsian secara umum ditemukan memil iki kemampuan predikt if yang paling kuat dibandingkan dengan aspek- aspek yang 
lain. Yen et al (2007) juga menemukan bahwa keberfungsian keluarga memprediks $\mathrm{i}$ kecanduan in ternet, terutama ko nflik antara orangtua dan anak. Ora ngtua yang berko nflik dengan anak cenderung menolak untuk mengawasi anak termasuk di antaranya dalam memberi batasan-batasan penggunaan internet pada anak. Pada penelitian ini ditemukan adanya keter kaitan antara kontrol perilaku dengan kecanduan int ernet Kontrol perilaku diartikan sebagai pola ado psi keluarga dalam menangani perilaku, termasuk di dalamnya terkait dengan batasan-batasan aturan dan standar perilaku yang dapat diterima dan derajat keleluasaan yang diperbolehkan dalam batas-batas standar (Miller et al., 2000). Dengan demikian, keluasa an penggunaan internet pada anak ditentukan oleh sejauhmana keluarga memiliki aturan dan kontrol terhadap perilaku penggunaan internet.

Keberfungsi an keluarga secara umum berkaitan dengan berbagai macam bentuk kecanduan, termasuk kecanduan internet Tafà dan Baiocco (2009) meneliti tentang bagaimana sistem keluarga berkaitan dengan perilaku adiktif pada remaja. Mereka menemukan bahwa keti dakmampuan keluarga untuk berubah dan membangun ikatan emo sion al berkaitan dengan ketergantungan obat-obatan terlarang. Fakt or keluarga dipandang sebagai faktor penting dalam kaitannya dengan perilaku adiktif baik kecanduan internet maupun kecanduan alkohol pada r emaja (Yen et al., 2007). An ak yangmempersepsi lingkunganrumahnya tidak kondusif cenderung menjadikan internet sebagai pelarian, dan kesenangan yang diper oleh kar ena terko neksi dengan internet menjadi penguat persepsi negatif terhadap kondisi keluarganya.Kecanduan internet dapat diprediksikan oleh sej auhmana keluarga dapat memenuhi kebutuhan afeksi dan ketertarikan keluarga terhadap minat anggo ta keluarga. Chng, Li, Liau, dan Kho o (2015) men yatakan bahwa anak yang kurang memiliki kelekatan dengan orang tua cenderung bermasalah dengan penggunaan internet. Orangtua yang dipandang terlalu menghukum, kurang memberi dukungan, kur ang hangat dan kurang terlibat cenderung membauat anak menggunakan intern et secara berlebihan $(\mathrm{Li}$, Garland, \& Ho ward, 2014).

\section{SIMPULAN DAN REKOMENDASI}

Penelitian ini sejalan dengan penelitianpenelitian sebelumnya yang menyatakan bahwa keluarga menjadi faktor penting bagi kecanduan intern et. Fakt or keberfungsian keluarga yang paling penting dalam memprediksi kecanduan internet pada penelitian ini adalah respon afeksi yang sesuai, baik secara kuantitas maupun kualitas, terhadap anggota keluarga. F aktor-fakto r lain yang juga berpengaruh adalah batasan-batasan yang diberikan oleh keluarga terhadap anggota keluarga dalam penggunaan internet. 
Penelitian ini memberikan landasan bahw a perlu adanya pendekatan interv ensi berbasis keluarga dalam memecahkan masalah yang berkaitan dengan kecanduan inter net. Keluarga, terutama orangtua, perlu untuk memberi batasan-batasan dalam penggun aan inter net pada anggota keluarga. Ada banyak strategi yang bisa dikembangkan untuk membatasi penggunaan inter net diantaranya active co-use, technical restrictions, interactive restrictions, monitoring (Livingstone \& Helsper, 2008). Menurut Quinn (2016), startegi-strategi tersebut tidak s epenuhny a terbukti efekt if dalam mengurangi resi ko terpapar kecanduan internet. Meski pun demikian, startegi yang menekankan pada restriction atau ko ntrol dipandang paling efekt if untuk mengur angi resiko terpapar penggunaan internet berlebihan.

\section{DAFTAR PUSTAKA}

Beavers, R., \& Hampson, R. B. (2000). The Beavers systems model of family functioning. 128-143.

Brenner, V. (1997). Psychology of c omputer use: XLVII. parameters of internet use, abuse and addiction: the first 90 days of the internet usage survey. Psychological Reports, 80, 879-882.

Br on fenb renner, U. (1979). The ecology of human develo pment. Massach us etts: Harvard University Press.

Caplan, S. E., \& High, A. C. (2011). Online social interaction, psy chosocial well-being, and problematic internet use. In K. S. Young \& C.N. de Abreu (Eds.), Internetaddiction: a handbook and guide to evaluation and treatment (p. 314). New Jer sey: John Willey \& Sons.

Chng, G. S., Li, D., Liau, A. K., \& Kho o, A. (2015). Moderating effects of the family environment for par ental mediation and pathological internet use in youths. Cyberpsychology, Behavior, and Social Networking, 18(1), 30-36. https:// doi.org/10.1089/cyber.2014.0368

Chou, C., Condron, L., \& Belland, J. C. (2005). A review of the research on Internet addiction. EducationalPsychology Review, 17(4), 363-388. https://doi.org/ 10.1007/s10648-005-8138-1

Epstein, N. B., B aldw in, L. M., \& B ishop, D. S. (1983). The McMaster family assessment device. Journal of Marital and Family Therapy, 9(2), 171-180.

Epstein, N. B., Bishop, D. S., \& Levin, S. (1978). The McMaster Model of Family Functioning. Jou rnal of Marital and Fam ily Therapy, 4(4), 19-31. https: // do i.org/ $10.1111 / \mathrm{j} .1752$ 0606.1978.tb0053 7.x

Isfahani, N. (2013). The predictive role of the family internal fact ors in tendency the adolescent girls to Internet addiction. Journal of Educational and Management Studies, 3(4), 390-393.

Is kender, M., \& Ak in, A. (2010). Social selfefficacy, academic loc us of control, and internet addiction. Computers and Educa tion, 54(4), 1101-1106. https:// d o i . o r g / 10 . $10016 /$ j.compedu.2009.10.014

Ko, C. H., Yen, J. Y., Yen, C. F., Lin, H. C., \& Yang, M. J. (2007). Fact or s predictive for incidence and remission of internet addiction in young adolescents: A prospectiv e study. Cyberpsychology and Behavior, 10 (4), 545-551. https:// doi.org/10.1089/cpb.2007.9992

Kraut, R., Patters on, M., Lundmark, V., Kiesler, S., Mukopadhyay, T., \& Scherlis, W. (1998). Internet paradox: A social technology that reduces social 
involvement and psychological wellbeing? American Psychologist, 53 (9), 1017-1031. https://doi.org/10.1037/ 0003-066X.53.9.1017

Kus s, D. J., \& Griffiths, M. D. (2015). In ternet addiction in psychoteraphy. Basingstoke: Palgrave Macmillan.

Lewandowski, A. S., Palermo, T. M., Stinso n, J., Handley, S., \& Chamber s, C. T. (2010). Systematic review of family functioning in families of children and adolescents with chronic pain. Journal of Pain, 11(11), 1027-1038. https://doi.org/ 10.1016/j.jpain.2010.04.005

Li, W., Garland, E. L., \& Howard, M. O. (2014). Family factors in In ternet addiction among Chinese youth: A review of English - and Chin ese-language s tudies. Computers in Human Behavior, 31 (1), 393-411. https://doi.org/10.1016/ j.chb.2013.11.004

Liu, C. Y., \& Kuo, F. Y. (2007). A study of Internet addiction through the lens of the interpers onal theory. Cyberpsycho logy and Behavior, 10(6), 799-80 4. https:// doi.org/10.1089/cpb.2007.9951

Livingstone, S., \& Helsper, E. J. (2008). Parental mediation of children's internet use. Journal of Broadcasting and Electronic Media, 52(4), 581-599. https://doi.org/ 10.1080/08838150802437396

Miller, I. W., Ryan, C. E., Keitner, G. I., Bishop, D. S., \& Epstein, N. B. (2000). The McMaster approach to families: Theory, assessment, treatment and $\mathrm{research}$. Journal of Fa mily Therapy, 22(2), 168189. https: //doi.org/10.1111/14676427.00145

Morahan- Martin, J. (2008). I nternet abus e: emergingtrends and lingering questions. In A. Barak (Ed.), Psychologica laspects of cyberspace: theory, research, applications (p. 317). Cambridge: Cambridge University Press.

Morahan-Martin, J., \& Schumacher, P. (2003). Loneliness and social uses of the
Internet Computers in Human Behavior, 19(6), 659-671. https://doi.org/ 10.1016/S0747-5632(03)00040-2

Preec hawong, S., Zauszniewski, J. A., Heinzer, M. M. V., M usil, C. M., Kercsmar, C., \& Aswinanonh, R. (2007). Relationships of family functioning, self-esteem, and res ourceful co ping of Thai ado lescents with asthma. Issues in Mental Health Nursing, 28(1), 21-36. https://doi.org/ $10.1080 / 01612840600996208$

Quinn, S. (2016). Parenting the online child. In A. Attrill \& C. Fullwood (Eds.), Applied cyberpsychology: practicalapplications of cyberpsychological theory and research. h t tp s: / / doi.org / 10.1057 / 9781137517036

a enor man ci, Ö., a enor man ci, G., G üçlü, O., \& Konkan, R. (2014). Attachment and family functioning in patients with Internet addiction. General Hospital Psychia try, 36(2), 203-207. https://

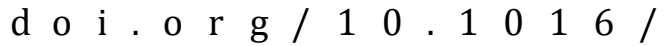
j.genhosppsych.2013.10.012

Shek, D. T. L., Tang, V. M. Y., \& Lo, C. Y. (2 008). Internetaddiction in Chinese adolescents in Hong Kong: Assess ment, profiles, and psych os ocial correlates. TheScientificWorldJournal, 8, 7 76-787. https://doi.or g/10.110 0/tsw.2008.104

Spada, M. M. (2014). An overview of problematic Intern et use. Addictive Behaviors, 39(1), 3-6. https://doi.org/ 10.1016/j .addb eh.2013.09.007

Tafà, M., \& Baiocco, R. (2009). Addictive behavior and family functioning during adolescence. American Journal of Family Therapy, 37(5), 388-395. https:// doi.org/10.1080/01926180902754745

Van Den Eijnden, R. J. J. M., Spijker man, R., Vermulst, A. A., Van Rooij, T. J., \& Engels, R. C. M. E. (2010). Com pulsiv e internet use among adolesc ents: Bidirectional pare nt-child relationships. Jo urnal of Abnormal Child Psychology, 38(1),77-89. https://doi.org/10.1007/s10802-0099347-8 
Wartberg, L., Kammerl, R., Ros enkranz, M., Hir schhäu ser, L., Hein, S., Schw inge, C., ... Thomasius, R. (2014). The inter dependence of family functioning and problematic internet use in a representative quota sample of adolescents. Cyberpsycholo gy, Behavior, and Social Networking, 17(1), 14-18. h t tps: / / doi.org / 10.1089 / cyber.2012.0494

Widyanto, L., \& Griffiths, M. (2007). Internet addiction: does it really exist? (revisited). InJ. Gackenbach(Ed.), Psychology and the Internet. https://doi.org/10.1016/B9780-12-3 69425-6.X5 017-6

Yen, J. Y., Yen, C. F., Chen, C. C., Chen, S. H., \& Ko, C. H. (2007). Family factors of internet addiction and substance use experience in Taiwanes e ado lesc ents. Cyberpsychology and Behavior, 10 (3), 323-3 29. https://doi.org/10.1089/ cpb.2006.9948

Young, K. S. (1998). Internet addiction: The emergence of a new clinical disorder. Cyberpsychology and Behavior, 1(3),237244. https://doi.org/10.1089/ cpb.1998.1.237

Yusuf, O. (2014, November 24). Penggunaan internet di indonesia nomor enam di dunia.pdf. Retr ieved January 15, 2015, from https: //tekno.kompas.com/read/ $2014 / 11 / 24 / 07430087 /$ Pengguna.Internet. Indonesia. Nomor.Enam.Dunia 